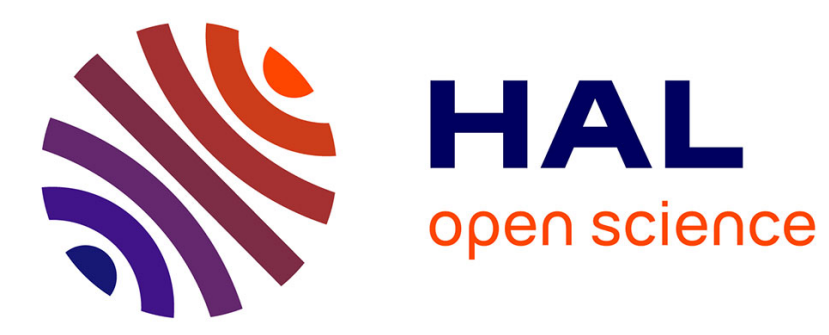

\title{
Services Evolution in Elderly Care Ecosystems
}

\author{
Thais A. Baldissera, Luis M. Camarinha-Matos
}

\section{To cite this version:}

Thais A. Baldissera, Luis M. Camarinha-Matos. Services Evolution in Elderly Care Ecosystems. 19th Working Conference on Virtual Enterprises (PRO-VE), Sep 2018, Cardiff, United Kingdom. pp.417429, 10.1007/978-3-319-99127-6_36. hal-02191163

\section{HAL Id: hal-02191163 \\ https://hal.inria.fr/hal-02191163}

Submitted on 24 Jul 2019

HAL is a multi-disciplinary open access archive for the deposit and dissemination of scientific research documents, whether they are published or not. The documents may come from teaching and research institutions in France or abroad, or from public or private research centers.
L'archive ouverte pluridisciplinaire HAL, est destinée au dépôt et à la diffusion de documents scientifiques de niveau recherche, publiés ou non, émanant des établissements d'enseignement et de recherche français ou étrangers, des laboratoires publics ou privés. 


\title{
Services Evolution in Elderly Care Ecosystems
}

\author{
Thais A. Baldissera and Luis M. Camarinha-Matos \\ Centre Technology and Systems - UNINOVA \\ Faculty of Sciences and Technology, NOVA University of Lisbon \\ Caparica, Portugal \\ tab@uninova.pt, cam@uninova.pt
}

\begin{abstract}
The aging process typically requires personalized care services for each individual. In this context, a collaborative elderly care ecosystem can support the provision of integrated services that may combine contributions from multiple providers. Through composition of services a personalized solution, tailored to the individual customer, respecting her/his requests, preferences, lifestyle, and constraints, can be achieved. An additional issue the ecosystem must deal with is the problem of evolution, as individual's care needs are not static over time. Consequently, the care services need to evolve accordingly to keep the elderly's requirements satisfied. This process of services' adaptation is challenging since many services can be dependent on each other, and there are various constraints that need to be observed before adaptating and enacting new services. In this paper, we exploit socio-technical aspects of service adaptation in the context of elderly care ecosystems. Starting with a service personalization method previously proposed, we introduce various cases of evolution of elderly care services in response to new requirements. The method considers customer's inputs and suggests evolution plans based on the MAPE-K methodology. An application example is then introduced to illustrate the approach.
\end{abstract}

Keywords: Elderly Care Ecosystem, Service Evolution, Service Composition and Personalization, Collaborative Networks.

\section{Introduction}

The world's elderly population has been increasing at an impressive rate in the last decades. By 2050, it is estimated that seniors over 80 will represent an increase of $205 \%$ in relation to 2017[1]. In various parts of the world, elderly will exceed the number of adolescents, which calls the attention for the aging process in our society $[1 ; 2]$. With aging, extra care needs are required to safeguard seniors and increase their life quality. In this process, each individual elderly may require specific assistance (e.g., care and help) depending on his/her life setting, involved relatives, health status, preferences, and constraints. Thus, a care service may be perfectly adequate for an individual and extremely purposeless for another.

In this context, the need for creating personalized (respecting preferences, limitations, living context) and evolving services becomes crucial with the changing conditions of the senior [3]. For instance, when moving to a new address, new care needs are identified, when some care need becomes obsolete or when the involved persons, financial constraints, etc., change there is a need to find the best sserviceprovider pairs for the new context. 
Addressing this challenge, this paper proposes a method to adapt services to evolving needs in the context of an Elderly Care Ecosystem (ECE) [4] focusing on supporting collaborative multi-stakeholder services. The remainder of this paper is structured as follows: Section 2 describes the motivation scenario; Section 3 presents a brief overview of ICT and Aging projects; Section 4 presents the relevant information available in ECE; Section 5 describes the solution (\{service, provider\} pair) personalization and composition method (the SCoPE method) and Section 6 introduces the SEvol method to evolve customer's solution in accordance with new requests and changes in life context. Finally, in Section 7 conclusions and directions for future work are presented.

\section{Motivating Scenario}

In order to guide the presentation of the proposed approach, let us consider a motivating scenario. Anna is an 82-years old, retired woman that lives alone, and suffers from hypertension, has cognitive disabilities, and movement constraints. Three years ago, she had an accident, and since then her health is under monitoring in her smart home which is equipped with various sensors and smart devices. Examples of some of these devices are automatic doors and windows opening devices, instantaneous 112 and her son callers, light switches, remote controllers for multimedia devices, smart bracelet which sends information to her doctor's central desk about her blood pressure and movements during the day, etc. In addition, her son (John) takes her to physical therapy twice a week. Anna had an assistant to clean and cook, but as in the last medical appointment, the doctor gave her a specific diet because her blood tests revealed a beginning of diabetes, Anna and her son decided to buy ready meals at a company specialized in diets for people with diabetes. John is also worried because he was assigned by his company to attend a training course abroad with one-month duration. This will change Anna's therapy routine because he will not be able to take his mother to therapy during this period. As such, a transport service to take Anna to treatment will be contracted.

\section{Some Projects on ICT and Aging}

Recent progress on technological devices and infrastructures creates the opportunity for new classes of services for elderly people [5]. This trend is reflected in a large number of research initiatives on ICT and aging during the last decade. This is clearly illustrated by an analysis of 190 projects started since 2001 as part of ICT and Aging agenda of European framework programs [6].

Fig. 2 ECE Partial Conceptual Modelshows the distribution of projects in terms of developed services. From the 190 projects, 168 consider a simple provider and 22 consider collaborative providers in the four life settings defined by the BRAID Bridging Research in Ageing and ICT Development - roadmap project [7]: Independent living, health and care, occupation in life, and recreation in life. 


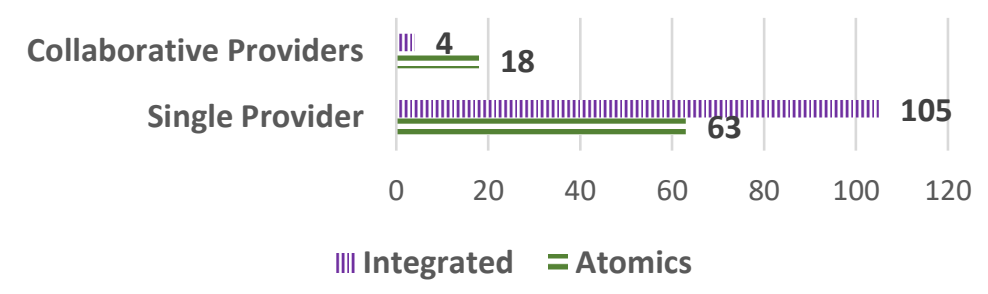

Fig. 1 Projects in the Aging Domain - mode of service provision

The older projects from 2001 to 2008 had focused on services by single providers. The concern was to meet the maximum service level by the same provider. The AMIGO project [8] - Ambient Intelligence for the Networked Home Environment - was one of the first addressing collaborative providers with integrated services in 2004. Although AMIGO was not specifically for aging solutions, the project suggested solutions for independent living that were promising and followed by other projects. Since 2009, projects aimed at single providers continue but a large project aimed at elderly health, the EMOTION-AAL [9] project, effectively focused on services delivered through various providers in the context of Europe. The aim of EMOTION-AAL is to develop an integrated healthcare concept for elderly people in rural areas in Europe. In this project an integrated solution for the elderly was developed based on seamless inclusion of social services and new technologies in rural areas, named "The Emotional Village". The project includes intense support for self-care and prevention and assistance to carry out daily activities, health and activity monitoring, enhancing safety and security.

Since 2010 to 2015,21 other projects have been funded, which focus on collaborative providers. Of these projects, 18 deliver atomics services such as INCLUSIONSOCIETY, MYLIFE, HOST, SAAPHO, CARE@HOME, LILY, MEDIATE, CARERSUPPORT, OSTEOLINK, AWARE, GO-MYLIFE, JOIN-IN, HELASCOL, ANIMATE, GIVE\&TAKE, ELDERS-UP!, SPONSOR and ACTGOGATE, for independent living, occupation in life, and recreation in life. The other 3 develop integrated services, CARE4BALANCE, AAL4ALL and T\&TNET projects, all with greater focus on independent living. This analysis points to a potential market expansion, especially in the areas of occupation in life and recreation in life. Other projects are in progress (starting in 2016) and more details about each project can be seen in [6].

\section{Elderly Care Ecosystem}

An Elderly Care Ecosystem (ECE) shall include various elements, namely the seniors (customers) profile and their current care needs, available care services, service providers entities, among others $[4 ; 10 ; 11]$.

From the information modelling perspective, ECE comprises various "environments" or zones. Relevant information about the elderly (which is identified as a customer within ECE) characterizes the Customer environment. The set of needs 
of individuals within the elderly community is established in the Care Needs environment. Providers deliver care services. Therefore, the set of care services offered by ECE is organized in a Service environment and the group of service providers in a Service Provider environment.

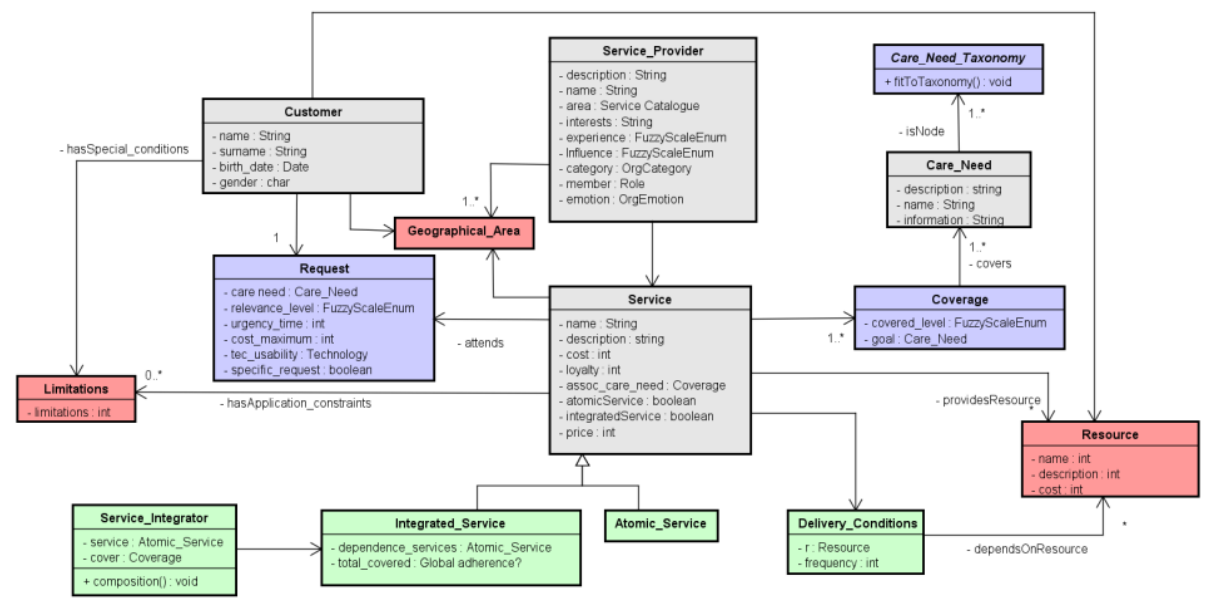

Fig. 2 ECE Partial Conceptual Model

Fig. 2 shows a partial conceptual model with the main elements of ECE (a more detailed ECE model is presented in [10]). The Customer and Service are linked by Request, representing the customer's demand and preferences. Coverage represents the connection between Service and Care_Need describing the coverage level of the covered care need taxonomically organized in a Care_Needs_Taxonomy.

Limitations, Geographical_Area and Resource indicate hard restrictions which can limit the availability of a service (or service provider) to a specific customer. For instance, if the service provider does not cover the customer's location, or if the customer has a special condition (e.g., Alzheimer disease) and the service presents application constraints for this situation, or even if the customer has a need for a resource (e.g., tablet, wi-fi internet, caregiver) which she/he does not have for the operation of the service, etc., then such constraints need to be taken into account.

A service might have conditions of delivery (Delivery_Conditions) based on parameters, for instance, needed resources (e.g., a bracelet) and frequency (e.g., three times a week). These parameters can change the business process regardless of service provision.

In the collaborative networks domain, an atomic service is represented by a single business service and an integrated service indicates a composition of atomic services. In our model, a service can be atomic (Atomic_Service) or integrated (Integrated_Service). A Service_Integrator entity is responsible for the composition of integrated services.

\section{Service Composition and Personalization}

In the elderly care domain, personalization involves the analysis of the senior's life context. The organization responsible for delivering care and assistance services (in our 
case, the ECE) identifies specific requirements for the customer's context and builds (or composes) a service solution to fit the needs.

In a previous work, the SCoPE (Service Composition and Personalization Ecosystem) method was proposed to support the process of composing and personalizing services in a collaborative network environment for elderly care.

SCoPE (see Fig. 3) is based on three main steps: (i) scope filtering - responsible for matching and excluding \{service, provider\} pairs based on the care need taxonomy, (ii) adherence calculation - resulting in the first rating of \{service, provider \}airs based on adherence multidimensional matrix for a specific customer, and (iii) service composition and ranking - using strategies for service composition and offering a list of potential solutions.

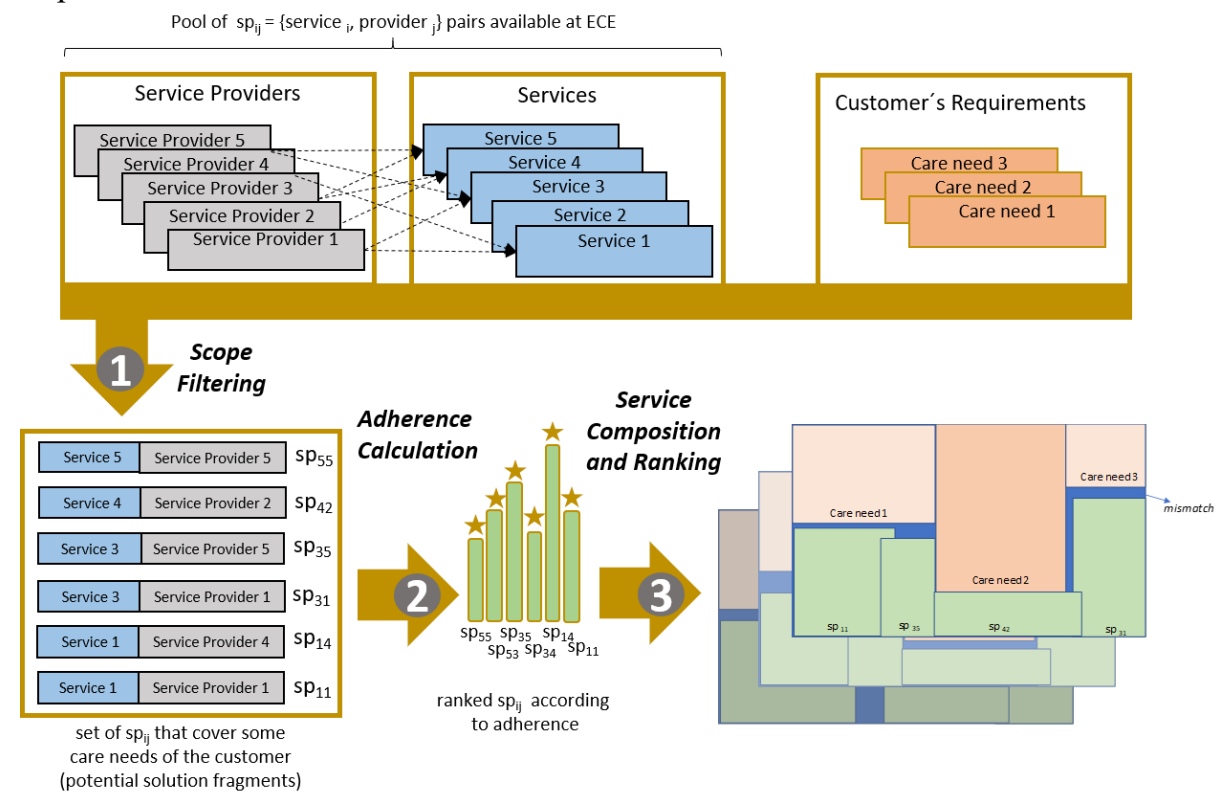

Fig. 3 SCoPE Method Overview

In Scope Filtering (step 1), available services (and corresponding providers) that cover some of the customer's care needs are identified, excluding those that are unsuitable due to geographical restrictions, special conditions, unavailable resources, and other hard constraints. The \{service, provider pair must guarantee that the service attends some customer's care needs, ensuring a proper personalization and adapting to the feedback received from both the ECE, the VO partners, the customer and her/his relatives, certifying in this way a current service personalization.

The Adherence Calculation (step 2) identifies personal customer's requests and characteristics for service adherence evaluation taking into consideration cultural differences, religious constraints, social aspects, place of living, etc.

Adherence represents a compatibility relation between the individual customer and a solution fragment $s p_{i j}$ (service $s_{i}$ and respective provider $p_{j}$ ) and it is calculated by estimating four coefficients: Closeness (CL), Partial Adherence (PA), Adherence (AD), and Global Adherence (GA). $C L$ is represented by a multidimensional matrix of the 
"proximity" between customer's requests and the features of the \{service, provider pair fragment. $P A$ is an intermediate computation that refines the closeness based on criteria's weights ponderation. Finally, $A D$ represents the resulting adherence according to the service's coverage level to each care need, and $G A$ represents the adherence considering all care needs together.

Table 1 summarizes the adherence calculation process, including the goal, inputs, and outputs for each step.

Table 1. Steps of Adherence Calculation Process

\begin{tabular}{|c|c|c|c|}
\hline \multicolumn{2}{|r|}{ Adherence Calculation Process } & Input & Output \\
\hline \multicolumn{2}{|c|}{$\begin{array}{l}\text { Step 1. Criteria's weights definition } \\
\text { Goal. Define criteria's weights }\end{array}$} & $\begin{array}{l}\text { Decision-making criteria } \\
\text { selected by the customer. }\end{array}$ & $\begin{array}{l}\text { Vector of } \\
\text { normalized weights: } \\
W=\left\{w_{1}, w_{2}, \ldots, w_{\text {cri }}\right\}\end{array}$ \\
\hline \multirow{3}{*}{$\begin{array}{l}\text { Repeated } \\
\text { for each } \\
\text { fragment } \\
\quad s p_{i j}\end{array}$} & $\begin{array}{l}\text { Step 2. Closeness Calculation } \\
\text { Goal. Calculate the closeness of } \\
\text { each } \mathrm{sp}_{\mathrm{ij}} \text { fragment against the } \\
\text { customer's requests }\end{array}$ & $\begin{array}{l}\mathrm{sp}_{\mathrm{ij}} \text { fragments features and } \\
\text { customer's requests }\end{array}$ & $\begin{array}{c}\text { Closeness vector: } \\
C L=\left\{c l_{1}, c l_{2}, \ldots, c l_{\text {cri }}\right\}\end{array}$ \\
\hline & $\begin{array}{l}\text { Step 3. PA calculation } \\
\text { Goal. Calculate the Partial } \\
\text { Adherence (PA), combining } \\
\text { criteria's closeness and criteria's } \\
\text { weights ponderation }\end{array}$ & $\begin{aligned} W & =\left\{w_{1}, w_{2}, \ldots, w_{\text {cri }}\right\} \\
C L & =\left\{c l_{1}, c l_{2}, \ldots, c l_{c r i}\right\}\end{aligned}$ & $P A$ coefficient \\
\hline & $\begin{array}{l}\text { Step 4. } A D \text { vector calculation } \\
\text { Goal. Calculate the Adherence } \\
(A D) \text { combining the } P A \text { and the } \\
\text { service coverage level about the } \\
\text { customer's individual care needs. }\end{array}$ & $\begin{array}{c}P A \text { coefficient; } \\
\text { Customer's care needs }(\mathrm{C} A) ; \\
\text { Service Coverage Level } \\
\text { regarding the care need. }\end{array}$ & $\begin{array}{c}A D \text { vector } \\
A D=\left\{a d_{1}, a d_{2}, \ldots, a d_{c a}\right\}\end{array}$ \\
\hline \multicolumn{2}{|c|}{$\begin{array}{l}\text { Step 5. GA matrix Calculation } \\
\text { Goal. Calculate the Global Adherence (all care } \\
\text { needs together) and build the solution } \\
\text { fragments and care needs mapping }\end{array}$} & $A D$ vector & $\begin{array}{l}G A \text { multidimensional } \\
\text { matrix }\end{array}$ \\
\hline
\end{tabular}

Service Composition and Raking (step 3) uses strategies for achieving a personalized result. Traditional methods for service composition involve human judgments and frequent step-by-step interaction with the customer and service provider (a kind of service co-design). In our approach, we keep the human decision, but mainly for the final stage where the best solutions have already been found easing decision making. The service composition process can then proceed using the group of $s p_{i j}$ fragments that have a reasonable adherence level. Various alternative composition methods can be considered, for instance with the purpose of adherence's maximization, number of services minimization or maximization, balanced number of providers, etc.

In the end, a customer's solution is presented through a vector representing the corresponding service and provider fragments $\left(\mathrm{sp}_{\mathrm{ij}}\right)$ and their adherence $(\mathrm{ad})$ to each care need $k$, the Global Adherence $(G A)$ and cost of the solution, and the relation between adherence and cost. For instance, considering Anna's scenario described above, she has four available solutions to choose as described in Table 2 (in our application example). Solution 1 presents the best adherence $(G A)$, but the highest costbenefit ratio is representing by solution 2 . Through the human interaction process, Anna will then choose her preferred solution. 
Table 2 Anna's Personalized Solutions

\begin{tabular}{l|c|c|c|c|c|c|c|c|c|c|c} 
& \multicolumn{3}{|c|}{ To bloodPressure care need } & \multicolumn{3}{c|}{ To homeSafety care need } & \multicolumn{3}{c}{ Global approach } \\
\cline { 2 - 13 } & $s p_{i j}$ & $a d$ & cost & ad/cost & $s p_{i j}$ & ad & cost & ad/cost & GA & Cost & $\begin{array}{c}\text { Ranking: } \\
\text { GA/cost } \\
(\%)\end{array}$ \\
\hline Solution 1 & $s p_{51}$ & 0.767 & $200 €$ & 0.383 & $s p_{22}$ & 0.927 & $40 €$ & 2.317 & 0.847 & $240 €$ & 0.770 \\
\hline Solution 2 & $s p_{64}$ & 0.639 & $75 €$ & 0.852 & $s p_{64}$ & 0.791 & $75 €$ & 1.055 & 0.715 & $75 €$ & 0.953 \\
\hline Solution 3 & $s p_{11}$ & 0.728 & $100 €$ & 0.728 & $s p_{21}$ & 0.782 & $30 €$ & 2.607 & 0.755 & $130 €$ & 0.581 \\
\hline Solution 4 & $s p_{51}$ & 0.767 & $200 €$ & 0.383 & $s p_{21}$ & 0.782 & $30 €$ & 2.607 & 0.774 & $230 €$ & 0.337 \\
\hline
\end{tabular}

\section{Service Evolution Process in ECE}

For each new context change, the ECE broker analyses the situation (in collaboration with the relevant stakeholders) and adapts the service to fit that context. In other words, the service solution evolves to cope with the new life stage. Under this perspective, the notion of evolutionary service [12-14] means that the provided service adapts to the senior's needs, and to any changes that affect the senior's life context.

Based on the $M A P E-K$ framework [15], this section presents a self-adaptive system approach for service evolution into ECE. After the $S C O P E$ process, the customer is assisted by a personalized solution (customer's solution). This solution represents the initial knowledge $K$ : the current service(s) and provider(s) which attend the customer's requirements. Fig. 4 illustrates this approach, which we call SEvol.

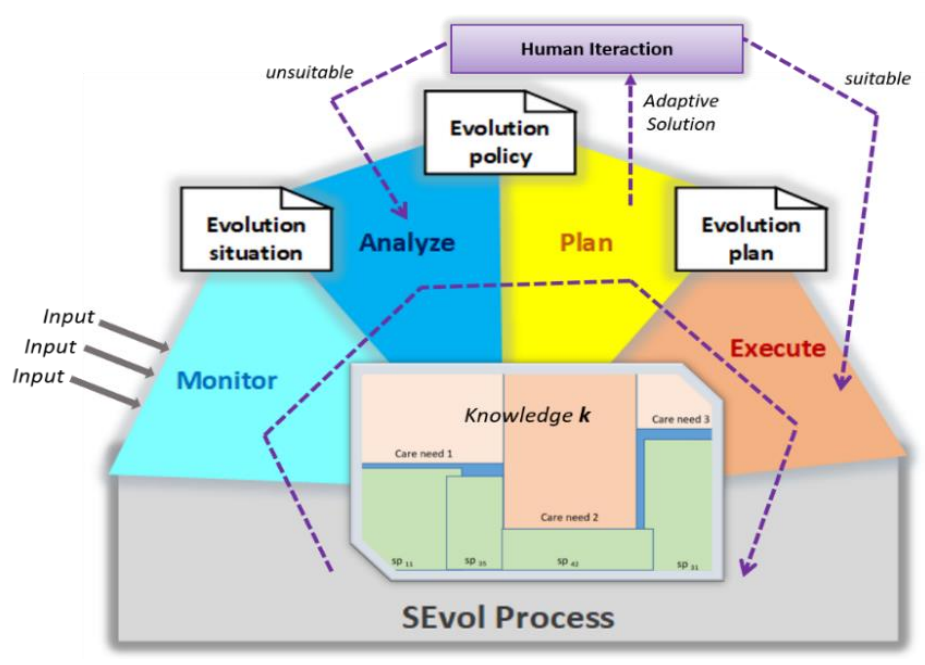

Fig. 4 Service Evolution Process - SEvol

The following phases are considered:

- Monitor phase receives a set of inputs which can come from several sources, for instance, from the customer and his/her family, or from the ECE, mainly represented by VO coordination, ECE management, or service provider. In this paper the main triggers of SEvol are those coming from the customer. 
- Analyze phase verifies if the current solution covers the new requests. If the current solution is unsuitable to cope with the environment changes, the Analyze function indicates the goals not covered by the solution (evolution situation) which will be the focus of the Plan function.

- The Plan phase considers the customer as unique, respecting his/her preferences and lifestyle and historical information available in ECE, and plans the solution evolution aiming a minimum of disturbance. With the designed evolution plan, the customer is contacted (human iteration). If she/he accepts the proposed solution, the execute phase starts, otherwise the process goes back to the analyze phase with the customer's feedback.

- The Execute phase is the responsible for finalizing the evolution process (implementation of evolutionary solution). Notice that the evolution should not be considered a new personalization since it does not seek the better possible results from scratch, but instead seeks a satisfactory solution with the least possible disturbance to the customer (that is already used to the specific characteristics of current solution).

\subsection{Evolution Plan}

The evolution (or adaptation) is based on customer's inputs. We consider as primary inputs to the evolution process: (a) the identified new care need, (b) identification that a care need is no longer present, or (c) identification that service changes the delivery conditions.

The proposed service evolution strategy into ECE is based on composition (or decomposition in case of fragment removal) of the current solution or the parameter change of delivery conditions. For each situation, the detailed strategy is presented below.

\subsubsection{Situation (a): adding a care need $x$}

The newly added care need should be connected to customer's solution; therefore, adding a new care need implies the adaptation of the integrated service and provider fragments. It is possible to classify this adaptation into two categories:

- (a1) Identifying (in the current solution) a service and provider fragment that covers the new care need (the solution is not changed).

- (a2) Adding a new service and provider fragment that cover the new care need.

In general, when a care need is added, the current solution is not prepared to attend this care need. So the process should identify if the current solution satisfies the new care need. If so, the process ends. Otherwise, the service and provider fragments which cover the new care need $\boldsymbol{x}$ are identified in order to extend the current solution (based on adherence resulting from SCoPE process).

Fig. 5 shows (at a high level) the sequence of adaptation the new customer request. 


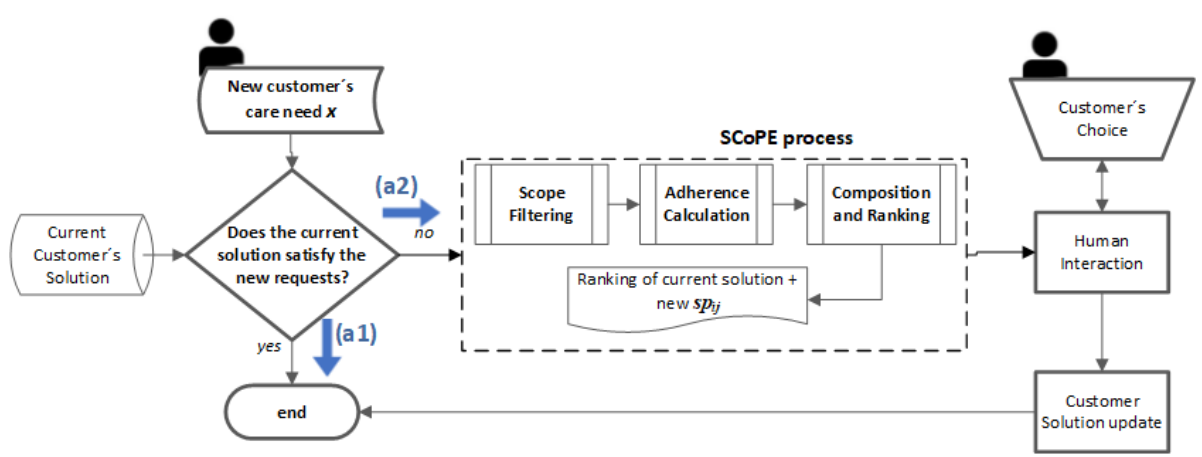

Fig. 5 Situation (a) - Evolution plan for customer's care need addition.

\subsubsection{Situation (b): removing a care need $x$}

This removal should not affect the current solution for other care needs. So, two strategies are considered:

- (b1) Removal of \{service, provider\} pair that covers the $\boldsymbol{x}$ care need.

- (b2) Change of \{service, provider\} pair that jointly covers $x$ and other care needs (for instance a care need $\boldsymbol{y}$ ).

The immediate removal of a \{service, provider\} pair fragment can only be done if it is exclusively attending the $\boldsymbol{x}$ care need. Otherwise, the fragment that is attending care need $\boldsymbol{y}$ (that is covered by the same solution fragment) can be updated if there is a better service adherence to $\boldsymbol{y}$. This process can be repeated when other care needs also are covered by the same fragment. A workflow of the evolution plan to customer's care needs removal is illustrated in Fig. 6.

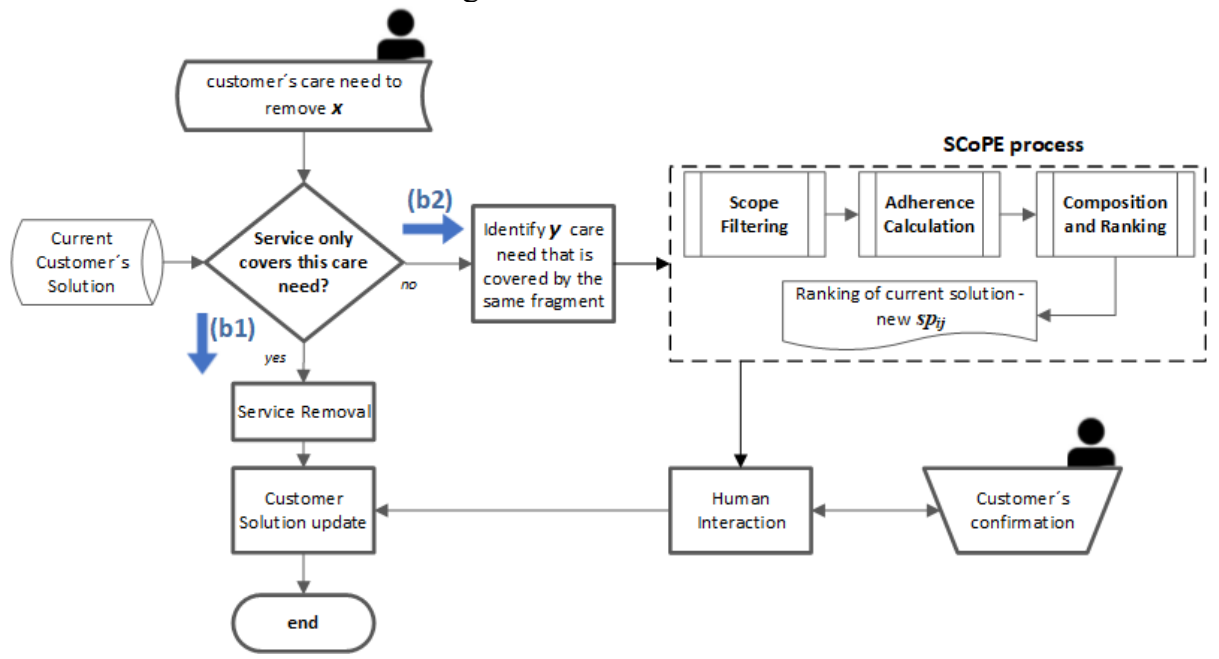

Fig. 6 Situation (b) - Evolution plan to customer's care needs removal 


\subsubsection{Situation (c): modifying parameters of a care need}

In this situation, the customer's care needs remain the same. However, specific requests are modified in ECE [10], for example, the customer usually requires a transportation service once a week, but for the next month, it will be twice a week (frequency parameter); the customer had a collective transportation service, but now she/he wants private (service features parameter), etc.

The evolution plan to change a customer's care need parameter (Fig. 7) involves two stages:

- (c1) Identify the parameter which should be changed checking if it is available in the current solution.

- (c2) Find a \{service, provider\} pair available that attends the new parameter.

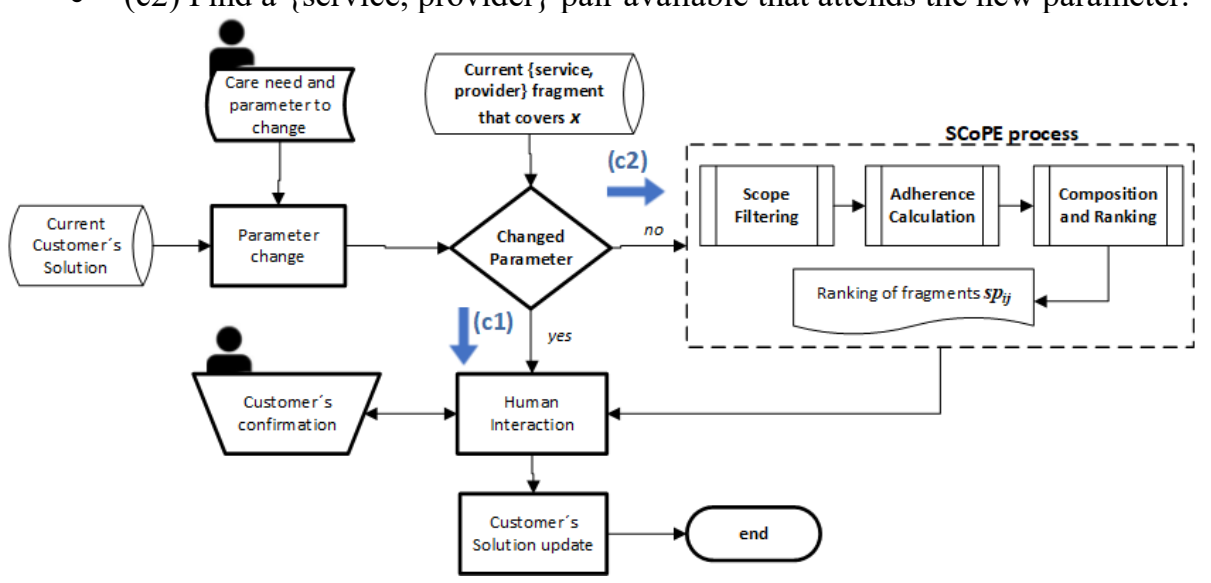

Fig. 7 Evolution plan for customer's care need parameters change

\subsection{Evolution Planning Application}

Each situation of the evolution plan is exemplified taking into account the solutions shown in Table 2 (Section 4). Let us imagine that Anna has chosen the solution 3 ( $\mathrm{sp}_{11}$, $\mathrm{sp}_{21}$ ) two/three years ago, and now she also needs the transportation service (newly identified care need $n$ ), and the solution will evolve. In the first analysis, $\mathbf{s p}_{21}$ service covers the homeSafety care need, but the ECE verifies that it is also available for transportation services covering the new request and representing a (a1) evolution plan. The solution is the same with new aggregated values (GA, Cost, and Ranking: GA/Cost $(\%))$. On the other hand, if the current solution is solution $2\left(\mathrm{sp}_{64}\right)$, a new sserviceprovider\} pair would have to be found to compose the solution representing a (a2) evolution plan.

The same solution 3 , in the (b) situation that removes the care need $m$ (for instance, Anna no longer needs bloodPressure care need) the $\mathrm{sp}_{11}$ pair is removed from the current solution representing a (b1) evolution plan. However, considering solution 2, $\mathrm{sp}_{64}$ pair covers both care needs (bloodPressure and homeSafety) and cannot be immediately removed (b2 situation). 
In the last evaluation plan, a parameter of service needs to be changed, for instance, Anna measures the tension once a day, but now she needs three times a day, frequency parameter is modified (c1 evolution plan), or if it is not possible, a new service is found to replace the existing one.

\section{Conclusions and Future Work}

One of the most significant challenges of ageing population will be to ensure sustainability, while guaranteeing proper care for elderly without creating a heavy burden on younger age groups, both in cost and life dependency. Collaborative technologies represent a significant impeller to active ageing mainly through a collaborative business ecosystem which, on the one hand, offers new business opportunities to service providers who work together and can evolve their business, as well as the elderly who can meet demands through personalized and always up-to-date services.

In this context, an Elderly Care Ecosystem has the potential to provide an environment where personalized and evolutionary solutions might increase customer's satisfaction, allow costs and risks sharing and strengthen providers' business.

In this paper, an overview of the SCoPE method highlights its support to the process of composing and personalizing services. Further, we propose a service evolution method (SEvol) to support the adaptation process (evolution) of current customer's solution to new requests. This proposal is intended to provide an adaptive system that can work well with an ECE framework to service personalization, composition, and evolution. In this sense, its validation depends on the acceptability, appropriateness, and feasibility of the approaches, models, and developments within the domain of elderly care ecosystem in collaborative networks environment.

As part of future work, we intend to further detail the service evolution conceptual model, examine from the market perspective how the ECE can be built (or composed) from the existing service providers and actors, and validate the algorithms used for prototype implementation.

Acknowledgment. This work has been funded in part by the Center of Technology and Systems (CTS - Uninova) and the Portuguese FCT-PEST program UID/EEA/00066/2013, and by the Ciência Sem Fronteiras Program and Instituto Federal Farroupilha (Brazil).

\section{References}

1. Kearney, A. T. (2013). Understanding the Needs and Consequences of the Ageing Consumer. The Consumer Goods Forum. Retrieved 10/10/2017, 2017, from https://www.atkearney.com/documents/10192/682603/Understanding+the+Needs+and +Consequences+of+the+Aging+Consumer.pdf/6c25ffa3-0999-4b5c-8ff1-afdca0744fdc

2. Bureau, P. R. (2017). World population data Retrieved 05/10/2017, from http://www.worldpopdata.org/index.php/map

3. Baldissera, T. A., \& Camarinha-Matos, L. M. (2016). Services personalization approach for a collaborative care ecosystem. In H. Afsarmanesh, L. M. Camarinha-Matos \& A. 
Lucas Soares (Eds.), Collaboration in a Hyperconnected World, 2016 (pp. 443-456). Cham: Springer doi: 10.1007/978-3-319-45390-3_38

4. Baldissera, T. A., \& Camarinha-Matos, L. M. (2016). Towards a collaborative business ecosystem for elderly care. In L. M. Camarinha-Matos, A. J. Falcão, N. Vafaei \& S. Najdi (Eds.), Technological Innovation for Cyber-Physical Systems, 2016 (pp. 24-34). Cham Springer doi: 10.1007/978-3-319-31165-4_3

5. Camarinha-Matos, L. M., Ferrada, F., Oliveira, A. I., Rosas, J., \& Monteiro, J. N. (2013). Integrated Care Services in Ambient Assisted Living. Paper presented at the IEEE 15Th Int. Conf. on e-Health Networking, Applications and Services (Healthcom 2013), Lisbon, 197-201.

6. AAL-Europe. (2001). ACTIVE AND ASSISTED LIVING PROGRAMME. from http://www.aal-europe.eu/

7. Camarinha-Matos, L. M., Afsarmanesh, H., Ferrada, F., Oliveira, A. I., \& Rosas, J. (2013). A comprehensive research roadmap for ICT and ageing. Studies in Informatics and Control, 22(3), 233-254. doi: 10.24846/v22i3y201301

8. Georgantas, N., Issarny, V., Mokhtar, S. B., Bromberg, Y.-D., Bianco, S., Thomson, G., Raverdy, P.-G., Urbieta, A., \& Cardoso, R. S. (2010). Middleware Architecture for Ambient Intelligence in the Networked Home. In H. Nakashima, H. Aghajan \& J. C. Augusto (Eds.), Handbook of Ambient Intelligence and Smart Environments (pp. 11391169). Boston, MA: Springer US.doi: 10.1007/978-0-387-93808-0_42

9. Maier, H.-O. (2010). EMOTION-ALL. from http://www.aaleurope.eu/projects/emotionaal/

10. Baldissera, T. A., Camarinha Matos, L. M., \& DeFaveri, C. (2017). Designing elderly care ecosystem in collaborative networks environment. In IEEE (Ed.), International Conference on Computing, Networking and Informatics. Ota, Lagos, Nigeria.doi: 10.1109/ICCNI.2017.8123818

11. Camarinha-Matos, L. M., Rosas, J., Oliveira, A. I., \& Ferrada, F. (2015). Care services ecosystem for ambient assisted living. Enterprise Information Systems, 9(5-6), 607-633. doi: 10.1080/17517575.2013.852693

12. O'Grady, M. J., Muldoon, C., Dragone, M., Tynan, R., \& O’Hare, G. M. (2010). Towards evolutionary ambient assisted living systems. Journal of Ambient Intelligence and Humanized Computing, 1(1), 15-29.

13. Hong, J., Suh, E.-H., Kim, J., \& Kim, S. (2009). Context-aware system for proactive personalized service based on context history. Expert Systems with Applications, 36(4), 7448-7457. doi: http://dx.doi.org/10.1016/j.eswa.2008.09.002

14. Brown, A., Johnston, S., \& Kelly, K. (2002). Using service-oriented architecture and component-based development to build web service applications. Rational Software Corporation.

15. IBM. (2006). An architectural blueprint for autonomic computing. IBM White Paper. Retrieved from https://www03.ibm.com/autonomic/pdfs/AC\%20Blueprint\%20White\%20Paper\%20V7.pdf 